Discussion Papers

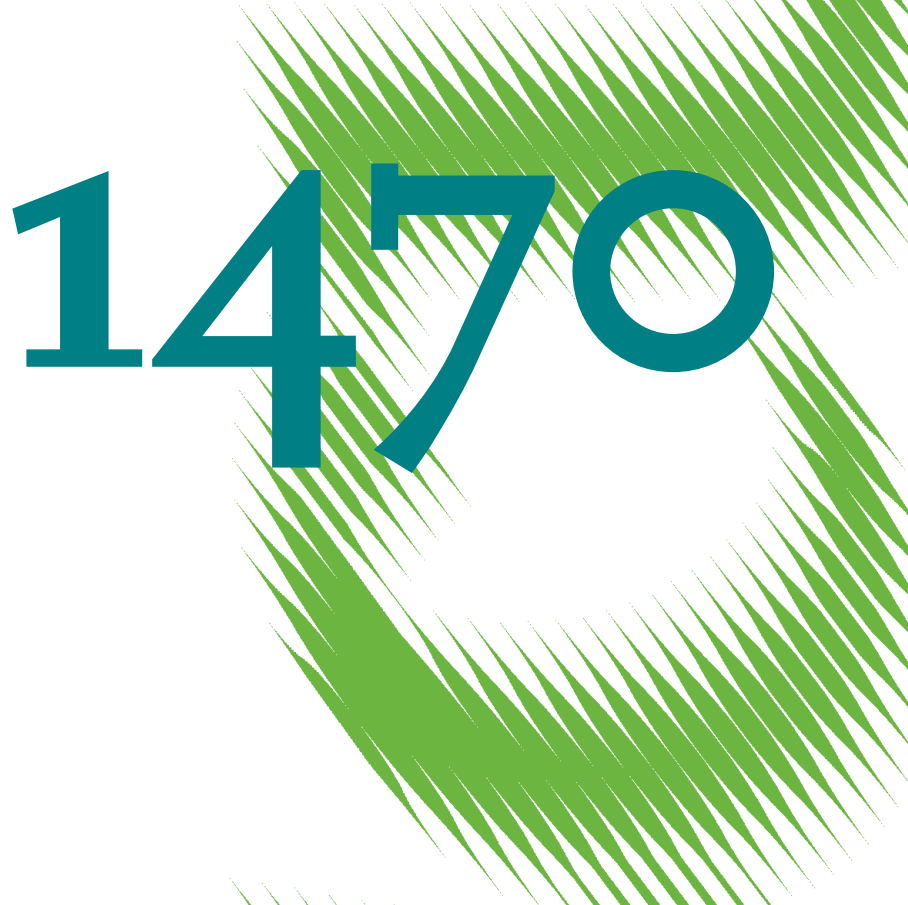

A Profit-Maximizing Approach for Transmission Expansion Planning Using a Revenue-Cap Incentive Mechanism 
Opinions expressed in this paper are those of the author(s) and do not necessarily reflect views of the institute.

IMPRESSUM

(C) DIW Berlin, 2015

DIW Berlin

German Institute for Economic Research

Mohrenstr. 58

10117 Berlin

Tel. +49 (30) $89789-0$

Fax +49 (30) $89789-200$

http://www.diw.de

ISSN electronic edition 1619-4535

Papers can be downloaded free of charge from the DIW Berlin website:

http://www.diw.de/discussionpapers

Discussion Papers of DIW Berlin are indexed in RePEc and SSRN:

http://ideas.repec.org/s/diw/diwwpp.html

http://www.ssrn.com/link/DIW-Berlin-German-Inst-Econ-Res.html 


\title{
A Profit-Maximizing Approach for Transmission Expansion Planning Using a Revenue-Cap Incentive Mechanism
}

\author{
Mohammad Reza Hesamzadeh \\ KTH Royal Institute of Technology, Sweden \\ (mrhesamzadeh@ee.kth.se) \\ Juan Rosellon \\ CIDE and German Institute for Economic Research (DIW), Germany \\ (jrosellon@diw.de) \\ Steven A. Gabriel \\ University of Maryland, U.S. \\ (sgabriel@umd.edu)
}

April 14, 2015

\begin{abstract}
This paper proposes an incentive mechanism for transmission expansion planning. The mechanism is a bilevel program. The upper level is a profit-maximizing transmission company (Transco) which expands its transmission system while endogenously predicts and influences the generation investment. The lower level is the optimal generation dispatch and investment. The Transco funds its transmission investment costs by collecting merchandising surplus and charging a fixed fee to consumers. The Transco is subject to a revenue cap set by the regulator. This mechanism is formulated as a mixed-integer, quadratically-constrained program (MIQCP) and applied to modified Garver and IEEE 24-node systems. The results of proposed approach have been compared with the welfaremaximum benchmark and cases of Transco with cost-plus regulation and no regulation. In all tested cases, the proposed approach results in welfaremaximum outcomes while the other regulatory approaches fail to produce welfare-maximum outcomes. The profit-maximizing approach has also been successful in cases where transmission investment is driven by demand growth and reactive Transco.
\end{abstract}

Keywords: revenue-cap regulation, transmission planning, electricity

JEL Codes: D24 · L51 - L94 


\section{Nomenclature}

$\begin{array}{ll}\text { Indices } & \\ t & \text { Planning period } \\ n & \text { Node } \\ i & \text { Demand } \\ j & \text { Existing generator } \\ k & \text { Candidate generator } \\ l & \text { Existing transmission line } \\ m & \text { Candidate transmission line } \\ \text { Parameters } & \\ \alpha_{i}>0 & \text { Intercept of linear utility } i(\$ / \mathrm{MWh}) \\ \beta_{i}<0 & \text { Slope of linear utility } i(\$ / \mathrm{MW} \text { h) } \\ c_{j} & \text { Marginal cost of generator } j(\$ / \mathrm{MWh}) \\ \widehat{c}_{k} & \text { Marginal cost of generator } k(\$ / \mathrm{MWh}) \\ \bar{C}_{m} & \text { Investment cost of line } m(\$) \\ C_{k} & \text { Investment cost of generator } k(\$) \\ J_{n, j}, K_{n, k} & \text { Incidence matrix for generators } \\ I_{n, i} & \text { Incidence matrix for demands } \\ S_{n, l}, \bar{S}_{n, m} & \text { Matrix of sending nodes of lines } \\ R_{n, l}, \bar{R}_{n, m} & \text { Matrix of receiving nodes of lines } \\ F_{l}\left(\widehat{F}_{m}\right) & \text { Maximum capacity of line } l(m)(\mathrm{MW}) \\ X_{l}\left(X_{m}\right) & \text { Reactance of line } l(m)(\mathrm{p} . \mathrm{u} .) \\ G_{j} & \text { Maximum production of generator } j(\mathrm{MW}) \\ D_{i} & \text { Maximum consumption of demand } i(\mathrm{MW}) \\ \Xi_{1}, \Xi_{2} & \text { Suitably large numbers } \\ \Upsilon(*) & \text { 1 if } * \text { is true and } 0 \text { otherwise } \\ & \end{array}$




$\begin{array}{ll}\text { Continuous } & \text { variables } \\ d_{i, t} & \text { Consumption of unit } i \text { in period } t(\mathrm{MW}) \\ g_{j, t} & \text { Production of unit } j \text { in period } t(\mathrm{MW}) \\ \widehat{g}_{k, t} & \text { Production of unit } k \text { in period } t(\mathrm{MW}) \\ f_{l, t}\left(\widehat{f}_{m, t}\right) & \text { Flow of line } l(m) \text { in period } t(\mathrm{MW}) \\ \theta_{n, t} & \text { Voltage angle at node } n \text { in period } t(\mathrm{p} . \mathrm{u} .) \\ \widehat{G}_{k, t} & \text { Investment for unit } k \text { in period } t(\mathrm{MW}) \\ \Phi_{t} & \text { Fixed charge of Transco to consumers }(\$) \\ \lambda_{n, t} & \text { Price at node } n \text { in period } t(\$ / \mathrm{MW}) \\ \tau 0_{k} & \text { Lagrange multiplier }(\$ / \mathrm{MW} \text { for: } \\ \xi_{t} & \text { no generation investment in period } 1 \\ \underline{\mu}_{l, t}, \bar{\mu}_{l, t}, \sigma_{l, t} & \text { slack bus constraint } \\ \bar{\sigma}_{m, t}, \underline{\sigma}_{m, t} & \text { line } l \text { constraints } \\ \underline{\nu}_{j, t}, \bar{\nu}_{j, t} & \text { line } m \text { constraints } \\ \underline{\phi}_{k, t}, \bar{\phi}_{k, t} & \text { generator } j \text { constraints } \\ \underline{\omega}_{i, t}, \bar{\omega}_{i, t} & \text { generator } k \text { constraints } \\ \text { Binary variable } \text { demand } i \text { constraints } \\ z_{m, t} & \text { Investment option for line } m \text { at period } t\end{array}$

\section{Introduction}

Optimal expansion of the transmission network is a major concern in electricity markets around the world. While generation and retail sectors have flourished under the forces of competition, the transmission sector has experienced a shortfall in necessary investment mainly because of lack of incentive mechanisms [1]. This has increased congestion in the transmission network [2]. The large-scale integration of renewable energy sources requires significant transmission expansion planning. Lack of investment incentives in the transmission sector exacerbates the situation and further increases transmission congestion costs [3]. Transmission congestion may increase market power in certain areas [4], and create entry barriers for new competitive generators. Accordingly, a well-functioning transmission network is a critical part of the wholesale and retail markets for electricity. The incentive problem for transmission expansion planning has been addressed in the relevant literature. Physical characteristics of electricity (such as loop flows), economies of scale, and dynamics between the forward transmission market and other markets are mentioned as complicating factors in analysis of incentives for transmission expansion planning [5], [6]. To tackle the incentive problem, the incremental surplus subsidy scheme (ISS) is proposed in [7]. References [8] and [9] propose price-cap mechanisms for incentivizing transmission expansion planning by a transmission company (Transco). Under certain conditions, these mechanisms lead to a transmission expansion plan which maximizes social welfare [10]. Reference [11] proposes a reward/penalty mechanism. In this mechanism, the regulator rewards the Transco when the transmission network is expanded and the congestion rents 
are decreased. Reference [12] proposes an out-turn mechanism. The out-turn is defined as the difference between actual electricity prices and prices without transmission congestion. The Transco is responsible for total out-turn cost and any transmission losses. The merchant mechanism proposed in [13] aims to bring competition into transmission expansion planning using the concept of financial transmission rights (FTR) [14]. References [10] and [15] extend the work in [8] and propose the HRV mechanism for transmission expansion planning. In the HRV mechanism, Transco maximizes its profit (sum of merchandising surplus and a fixed charge) subject to the price-cap constraint introduced in [8]. The HRV mechanism has been tested on simplified models of Northwestern Europe and the Northeast U.S. [10], [16]. Mathematically, the HRV model is a non-linear program with equilibrium constraints (NLPEC) and local optimizers have been used to solve the related model but with no guarantee of global optimality. Nevertheless, finding an optimal incentive mechanism for transmission expansion planning is an open question both in thory and in practice. The current paper contributes to the literature by proposing an alternative incentive mechanism for transmission expansion planning following the mechanisms in [8] and [10]. The revenue of the Transco consists of its network merchandising surplus and a fixed charge to consumers. The Transco maximizes its profit by expanding its transmission network. The profit-maximizing Transco is subject to a proposed revenue-cap constraint which is set by the regulator. The Transco also anticipates and influences optimal generation dispatch and investment (we disregard strategic behavior in the generation sector). The proposed revenue-cap regulatory constraint is linearized while the price-cap regulatory constraint in [8] has bilinear terms and cannot be linearized. Subsequently, the whole mechanism is reformulated as a mixed-integer, quadratically-constrained program (MIQCP) which can be solved to global optimality (contrary to the NLPEC of HRV model with no guarantee of global optimality). In all previous incentive models the discrete nature of transmission expansion ${ }^{1}$ and potential substitution between generation expansion and transmission expansion are ignored. In our proposed model, the transmission expansion is a discrete decision and the generation investment decisions are decided endogenously by the anticipatory, profit-maximizing Transco. We have also tested our proposed incentive mechanism when transmission expansion planning is driven by demand growth and when the generation expansion planning decisions are exogenous to the model (reactive Transco). The numerical results in this paper show that in all studied cases, the proposed mechanism incentivizes the Transco to expand the transmission network in a welfare-maximizing way. The rest of this paper is organized as follows. Section 3 presents the benchmark model for the proposed incentive mechanism. The proposed approach for transmission expansion planning is detailed in Section 4. To show the operation of the incentive mechanism an illustrative example is used in Section 5. The modified Garver and IEEE 24-node system are studied in Section 6. Two cases of transmission expansion

\footnotetext{
${ }^{1}$ Modeling marginal changes in transmission capacity is a poor representation of real transmission expansion which is charactrized by lumpiness and non-convexities [17].
} 
planning driven by demand growth and a reactive Transco are studied in Section 7. Section 8 concludes.

\section{The welfare-maximizing benchmark}

We assume a welfare-maximizing utility owning both generation and transmission assets. The welfare-maximizing expansion planning of joint generation and transmission system is set out in (1).

$$
\begin{aligned}
& \underset{\Omega_{s}}{\operatorname{Maximize}} \sum_{t}\left\langle\psi \left(\sum_{i}\left(\frac{1}{2} \beta_{i} d_{i, t}^{2}+\alpha_{i} d_{i, t}\right)-\sum_{j} c_{j} g_{j, t}-\right.\right. \\
& \left.\sum_{k} \widehat{c}_{k} \widehat{g}_{k, t}\right)-\sum_{m} \bar{C}_{m}\left(z_{m, t}-z_{m, t-1}\right)- \\
& \left.\sum_{k} \underline{C}_{k}\left(\widehat{G}_{k, t}-\widehat{G}_{k, t-1}\right)\right\rangle \\
& \text { Subject to } \\
& z_{m, t} \geq z_{m, t-1} \forall m, \forall t \geq 2, z_{m, t=1}=0 \forall m \\
& \widehat{G}_{k, t} \geq \widehat{G}_{k, t-1}\left(\tau_{k, t}\right) \forall k, \forall t \geq 2, \widehat{G}_{k, t=1}=0\left(\tau 0_{k}\right) \forall k \\
& \sum_{j} J_{n, j} g_{j, t}+\sum_{k} K_{n, k} \widehat{g}_{k, t}-\sum_{i} I_{n, i} d_{i, t} \\
& -\sum_{l} S_{n, l} f_{l, t}+\sum_{l} R_{n, l} f_{l, t}-\sum_{m} \bar{S}_{n, m} \widehat{f}_{m, t} \\
& +\sum_{m} \bar{R}_{n, m} \widehat{f}_{m, t}=0\left(\lambda_{n, t}\right) \forall n, t \\
& f_{l, t}-\frac{100}{X_{l}}\left(\sum_{n} S_{n, l} \theta_{n, t}-\sum_{n} R_{n, l} \theta_{n, t}\right)=0\left(\sigma_{l, t}\right) \forall l, t \\
& -F_{l} \leq f_{l, t} \leq F_{l}\left(\underline{\mu}_{l, t}, \bar{\mu}_{l, t}\right) \forall l, t \\
& \widehat{f}_{m, t}-\frac{100}{X_{m}}\left(\sum_{n} \bar{S}_{n, m} \theta_{n, t}-\sum_{n} \bar{R}_{n, m} \theta_{n, t}\right) \\
& \leq \Xi_{1}\left(1-z_{m, t}\right)\left(\bar{\sigma}_{m, t}\right) \forall m, t \\
& \widehat{f}_{m, t}-\frac{100}{X_{m}}\left(\sum_{n} \bar{S}_{n, m} \theta_{n, t}-\sum_{n} \bar{R}_{n, m} \theta_{n, t}\right) \\
& \geq-\Xi_{1}\left(1-z_{m, t}\right)\left(\underline{\sigma}_{m, t}\right) \forall m, t \\
& -z_{m, t} \widehat{F}_{m} \leq \widehat{f}_{m, t} \leq z_{m, t} \widehat{F}_{m}\left(\underline{\gamma}_{m, t}, \bar{\gamma}_{m, t}\right) \forall m, t \\
& 0 \leq g_{j, t} \leq G_{j}\left(\underline{\nu}_{j, t}, \bar{\nu}_{j, t}\right) \forall j, t \\
& 0 \leq g_{k, t} \leq \widehat{G}_{k, t}\left(\underline{\phi}_{j, t}, \bar{\phi}_{j, t}\right) \forall k, t \\
& 0 \leq d_{i, t} \leq D_{i, t}\left(\underline{\omega}_{i, t}, \bar{\omega}_{i, t}\right) \forall i, t \\
& \theta_{n=1, t}=0\left(\xi 0_{t}\right) \forall t
\end{aligned}
$$


The optimization problem (1) is a dynamic, mixed-integer, quadratic program (MIQP) over planning periods $(t)$. We assume a quadratic utility function for demand, linear generation operation and investment costs, and linear transmission investment costs in the objective function (1a). The objective function is to maximize the sum of social welfare over different planning periods. $\psi$ is the discount factor which makes the short-term social welfare and long-term investment costs comparable. By constraints (1b) and (1c), the first period is assumed to have no generation-transmission investment and investments are understood to be cumulative. Energy balance at each node is modeled in (1d). Constraints (1e) and (1f) calculate the power flows through existing transmission lines and bound the calculated power flows by thermal limits of the lines (base of 100 MVA is used to change the p.u. power flow values to actual MW values). Constraints $(1 \mathrm{~g}),(1 \mathrm{~h})$, and (1i) model the investment in new transmission lines and bound their power flows by thermal capacities of these new lines. The $\Xi_{1}$ is a suitably large constant. The maximum generation capacities of existing and new generators are modeled in constraints $(1 \mathrm{j})$ and $(1 \mathrm{k})$. The maximum consumption for each demand point in each planning period is modeled in (11). Constraint (1m)

sets node 1 as the reference node. $\Omega_{s}=\left\{z_{m, t}, \widehat{G}_{k, t}, d_{i, t}, g_{j, t}, \widehat{g}_{k, t}, f_{l, t}, \widehat{f}_{m, t}, \theta_{n, t}\right\}$ is the set of decision variables considered. As it is commonly assumed in the engineering literature ([18], [19]) a single load scenario corresponding to forecasted peak load in each planning period $\left(D_{i, t}\right)$ is considered. The results of the optimization problem (1) are used as the benchmark for measuring the economic efficiency of our proposed transmission expansion planning approach.

\section{The profit-maximizing transmission expansion planning}

We assume an independent regional transmission company (Transco) who owns the transmission network. The Transco does the transmission expansion planning, bears the costs, and collects the revenues. The Transco revenue consists of its network merchandising surplus (total payoff from demand minus total payment to generators) and a fixed charge $\left(\Phi_{t}\right)$ per planning period $t$. The fixed charge is a charge to consumers to fund the transmission expansion costs. This 
profit-maximizing Transco can be modeled via a bilevel program shown in (2).

$$
\begin{aligned}
& \underset{z_{m, t}, \Phi_{t}}{\operatorname{Maximize}} \sum_{t}\left\langle\sum_{n, i} I_{n, i} \lambda_{n, t} d_{i, t}-\sum_{n, j} J_{n, j} \lambda_{n, t} g_{j, t}\right. \\
& \left.\left.-\sum_{n, k} K_{n, k} \lambda_{n, t} \widehat{g}_{k, t}\right)+\Phi_{t}-\sum_{m} \bar{C}_{m}\left(z_{m, t}-z_{m, t-1}\right)\right\rangle \\
& \text { Subject to } \\
& z_{m, t} \geq z_{m, t-1} \forall m, \forall t \geq 2, z_{m, t=1}=0 \forall m \\
& \Phi_{t}-\left\langle\sum_{i}\left(\frac{\psi}{2} \beta_{i} d_{i, t}^{2}+\psi \alpha_{i} d_{i, t}\right)-\sum_{n, i} I_{n, i} \lambda_{n, t} d_{i, t}\right\rangle \leq \\
& (1+R+Y)\left\{\Phi_{t-1}-\left\langle\sum_{i}\left(\frac{\psi}{2} \beta_{i} d_{i, t-1}^{2}+\psi \alpha_{i} d_{i, t-1}\right)\right.\right. \\
& \left.\left.-\sum_{n, i} I_{n, i} \lambda_{n, t-1} d_{i, t-1}\right\rangle\right\}(\forall t \geq 2), \Phi_{t=1}=0 \\
& \text { Where }\left\{d_{i, t}, g_{j, t}, \widehat{g}_{k, t}, \lambda_{n, t}\right\} \in \\
& \arg \underset{\Omega_{s} / z_{m, t}}{\operatorname{Maximize}} \sum_{t}\left\langle\psi \left(\sum_{i}\left(\frac{1}{2} \beta_{i} d_{i, t}^{2}+\alpha_{i} d_{i, t}\right)-\right.\right. \\
& \left.\left.\sum_{j} c_{j} g_{j, t}-\sum_{k} \widehat{c}_{k} \widehat{g}_{k, t}\right)-\sum_{k} \underline{C}_{k}\left(\widehat{G}_{k, t}-\widehat{G}_{k, t-1}\right)\right\rangle \\
& \text { Subject to }(1 c)-(1 m)
\end{aligned}
$$

The Transco maximizes its profit over planning periods $(t)$ subject to a regulatory constraint on its fixed-charge component $\left(\Phi_{t}\right)$ of its revenue. The regulatory constraint sets an upper bound on the fixed charge. The upper bound is the sum of the fixed charge in the previous planning period and change in consumer surplus between current planning period and the previous one. Under the proposed structure, the profit-maximizing Transco is willing to cede some merchandising surpluses in exchnage of an increase in the fixed charge. Mathematically, this revenue-cap regulatory constraint can be written as (2c) where $\mathrm{R}$ and $\mathrm{Y}$ are inflation and efficiency factors set by the regulator (in this paper they are set to 0 for sake of mathematical brevity), respectively. The Transco anticipates and influences the generation dispatch and investment resulting from its transmission planning decisions. In an environment of price-taking generators and loads, the optimal generation dispatch and investment can be modeled as optimization problem (2d)-(2e). This optimization problem is a convex quadratic program (QP) in minimization where the transmission planning decisions are exogenously set by the Transco. Accordingly, the interaction between the profit-maximizing Transco with revenue-cap regulation and optimal generation dispatch and investment can be modeled as the bilevel program (2). The upper level is the profit-maximizing Transco (2a)-(2b)-(2c) and the lower level is a convex QP (in minimization) for the generation dispatch and investment decisions (2d)-(2e). Since the lower level is a convex QP (in minimization), 
the Karush-Kuhn-Tucker (KKT) optimality conditions [20] are both necessary and sufficient. Hence, the lower-level optimization can be replaced by its KKT conditions. $^{2}$ Following [22] and [23], the complementary slackness conditions are replaced by the strong duality condition. This leads to less number of constraints and binary variables in the final model. The stationary conditions for the lower-level QP (2d)-(2e) are derived in (3).

$$
\begin{aligned}
& \psi \beta_{i} d_{i, t}+\psi \alpha_{i}-\sum_{n} I_{n, i} \lambda_{n, t}+\underline{\omega}_{i, t}-\bar{\omega}_{i, t}=0 \forall i, t \\
& -\psi c_{j}+\sum_{n} J_{n, j} \lambda_{n, t}+\underline{\nu}_{j, t}-\bar{\nu}_{j, t}=0 \forall j, t \\
& -\psi \widehat{c}_{k}+\sum_{n} K_{n, k} \lambda_{n, t}+\underline{\phi}_{k, t}-\bar{\phi}_{k, t}=0 \forall k, t \\
& \underline{C}_{k}+\tau 0_{k}-\tau_{k, 2}+\bar{\phi}_{k, 1}=0(t=1) \forall k \\
& \tau_{k, t}-\tau_{k, t+1}+\bar{\phi}_{k, t}=0(1<t<T) \forall k, t \\
& -\underline{C}_{k}+\tau_{k, T}+\bar{\phi}_{k, T}=0(t=T) \forall k \\
& -\sum_{n} S_{n, l} \lambda_{n, t}+\sum_{n} R_{n, l} \lambda_{n, t}+\sigma_{l, t}+\underline{\mu}_{l, t} \\
& -\bar{\mu}_{l, t}=0 \forall l, t \\
& -\sum_{n} \bar{S}_{n, m} \lambda_{n, t}+\sum_{n} \bar{R}_{n, m} \lambda_{n, t}+\underline{\sigma}_{m, t}-\bar{\sigma}_{m, t}+\underline{\gamma}_{m, t} \\
& -\bar{\gamma}_{m, t}=0 \forall m, t \\
& -\frac{100}{X_{l}} \sum_{l} S_{n, l} \sigma_{l, t}+\frac{100}{X_{l}} \sum_{l} R_{n, l} \sigma_{l, t}+\xi 0_{t} \Upsilon(n=1) \\
& -\frac{100}{X_{m}} \sum_{m} \bar{S}_{n, m} \underline{\sigma}_{m, t}+\frac{100}{X_{m}} \sum_{m} \bar{R}_{n, m} \underline{\sigma}_{m, t}+ \\
& \frac{100}{X_{m}} \sum_{m} \bar{S}_{n, m} \bar{\sigma}_{m, t}-\frac{100}{X_{m}} \sum_{m} \bar{R}_{n, m} \bar{\sigma}_{m, t}=0 \forall n, t
\end{aligned}
$$

\footnotetext{
${ }^{2}$ We have assumed that when the lower-level problem has multiple optimal solutions, that the one that is selected, related to the upper level is "optimistic" [21]. That is to say, the lower-level problem does not strive to make the upper-level problem worse.
} 
Let $A_{i, t}=-\frac{1}{\psi \beta_{i}}\left(\psi \alpha_{i}-\sum_{n} I_{n, i} \lambda_{n, t}+\underline{\omega}_{i, t}-\bar{\omega}_{i, t}\right)$, then the strong-duality condition is:

$$
\begin{aligned}
& -\sum_{i} \frac{1}{2} \psi \beta_{i} A_{i, t}^{2}+\sum_{i} D_{i, t} \bar{\omega}_{i, t}+\sum_{j} G_{j} \bar{\nu}_{j, t}+ \\
& \sum_{l} F_{l}\left(\underline{\mu}_{l, t}+\bar{\mu}_{l, t}\right)+\sum_{m} z_{m, t} \widehat{F}_{m}\left(\underline{\gamma}_{m, t}+\bar{\gamma}_{m, t}\right)+ \\
& \sum_{m} \Xi_{1}\left(1-z_{m, t}\right)\left(\bar{\sigma}_{m, t}+\underline{\sigma}_{m, t}\right) \\
& =\sum_{i}\left(\frac{1}{2} \psi \beta_{i} d_{i, t}^{2}+\psi \alpha_{i} d_{i, t}\right)-\sum_{j} \psi c_{j} g_{j, t}- \\
& \left.\sum_{k} \psi \widehat{c}_{k} \widehat{g}_{k, t}-\sum_{k} \underline{C}_{k}\left(\widehat{G}_{k, t}-\widehat{G}_{k, t-1}\right)\right\rangle \forall t
\end{aligned}
$$

Doing this, the initial bilevel model (2) is transformed into a mixed-integer, non-linear program (MINLP). The nonlinearities in the resulting MINLP model are: (a) the bilinear terms $\lambda_{n, t} d_{i, t}, \lambda_{n, t} g_{j, t}, \lambda_{n, t} \widehat{g}_{k, t}$ in the Transco profit function. (b) the bilinear terms $\Xi_{1}\left(1-z_{m, t}\right)\left(\bar{\sigma}_{m, t}+\underline{\sigma}_{m, t}\right)$ and $z_{m, t} \widehat{F}_{m}\left(\underline{\gamma}_{m, t}+\bar{\gamma}_{m, t}\right)$, (c) the terms $A_{i, t}^{2}$ and $d_{i, t}^{2}$ in the strong-duality condition, and (d) the nonconvex regulatory constraint (2c). Regarding the bilinear terms in (a), we have:

$$
\begin{aligned}
& \sum_{n, i} I_{n, i} \lambda_{n, t} d_{i, t}-\sum_{n, j} J_{n, j} \lambda_{n, t} g_{j, t}-\sum_{n, k} K_{n, k} \lambda_{n, t} \widehat{g}_{k, t} \\
& =\sum_{n} \lambda_{n, t}\left(\sum_{i} I_{n, i} d_{i, t}-\sum_{j} J_{n, j} g_{j, t}-\sum_{k} K_{n, k} \widehat{g}_{k, t}\right) \stackrel{(1 d)}{=} \\
& \sum_{l} f_{l, t}\left(-\sum_{n} S_{n, l} \lambda_{n, t}+\sum_{n} R_{n, l} \lambda_{n, t}\right)+ \\
& \sum_{m} \widehat{f}_{m, t}\left(-\sum_{n} \bar{S}_{n, m} \lambda_{n, t}+\sum_{n} \bar{R}_{n, m} \lambda_{n, t}\right) \stackrel{(3 g)(3 h)}{=} \\
& \sum_{l} f_{l, t}\left(\bar{\mu}_{l, t}-\underline{\mu}_{l, t}-\sigma_{l, t}\right)+\sum_{m} \widehat{f}_{m, t}\left(\bar{\gamma}_{m, t}-\underline{\gamma}_{m, t}+\bar{\sigma}_{m, t}-\right. \\
& \left.\underline{\sigma}_{m, t}\right)
\end{aligned}
$$

From (1e) and the complementary conditions for constraints (1f), (1g), (1h), and (1i), we have

$$
\begin{aligned}
& (5)=\sum_{l} F_{l}\left(\bar{\mu}_{l, t}+\underline{\mu}_{l, t}\right)+\sum_{m} \widehat{F}_{m} z_{m, t}\left(\bar{\gamma}_{m, t}+\underline{\gamma}_{m, t}\right)+ \\
& \underbrace{\Xi_{1}\left(1-z_{m, t}\right)\left(\bar{\sigma}_{m, t}+\underline{\sigma}_{m, t}\right)}_{T 1}+\underbrace{\theta_{n, t}(3 i)}_{T 2}
\end{aligned}
$$

If $z_{m, t}=1$, then term $T 1$ is zero. If $z_{m, t}=0$, then both constraints (1g) and (1h) are slack which means $\bar{\sigma}_{m, t}=\underline{\sigma}_{m, t}=0$ and accordingly $T 1=0$. 
Hence, $T 1$ is always zero. From $(1 \mathrm{~m})$ and (3i), it is obvious that $T 2$ is zero. By introducing $\widehat{\gamma}_{m, t}=z_{m, t}\left(\underline{\gamma}_{m, t}+\bar{\gamma}_{m, t}\right)$ and $\widehat{\gamma}_{m, t}-\left(\underline{\gamma}_{m, t}+\bar{\gamma}_{m, t}\right) \leq \Xi_{2}\left(1-z_{m, t}\right)$, $\widehat{\gamma}_{m, t}-\left(\underline{\gamma}_{m, t}+\bar{\gamma}_{m, t}\right) \geq-\Xi_{2}\left(1-z_{m, t}\right), \widehat{\gamma}_{m, t} \leq \Xi_{2} z_{m, t}, \widehat{\gamma}_{m, t} \geq-\Xi_{2} z_{m, t}$, the non-linear term $z_{m, t}\left(\underline{\gamma}_{m, t}+\bar{\gamma}_{m, t}\right)$ can be removed [24]. For quadratic terms, $A_{i, t}^{2}$ and $d_{i, t}^{2}$, we replace them with new variables $A 2_{i, t}$ and $d 2_{i, t}$ and add two constraints $A 2_{i, t} \geq A_{i, t}^{2}$ and $d 2_{i, t} \geq d_{i, t}^{2}$ to the formulation. For the non-convex regulatory constraint (2c), from stationary condition (3a) and complementary slackness conditions for (11), we have: $\left(\frac{\psi}{2} \beta_{i} d_{i, t}^{2}+\psi \alpha_{i} d_{i, t}\right)-\sum_{n} I_{n, i} \lambda_{n, t} d_{i, t}=$ $-\frac{\psi}{2} \beta_{i} A_{i, t}^{2}+D_{i, t}\left(\underline{\omega}_{i, t}+\bar{\omega}_{i, t}\right)=-\frac{\psi}{2} \beta_{i} A 2_{i, t}+D_{i, t} \bar{\omega}_{i, t}$. Now we can write the whole formulation of the profit-maximizing Transco as a dynamic and mixedinteger quadratically-constrained program (MIQCP). This MIQCP is shown in (7).

$$
\begin{aligned}
& \underset{\Omega_{p}}{\operatorname{Maximize}} \sum_{t}\left\langle\sum_{l} F_{l}\left(\bar{\mu}_{l, t}+\underline{\mu}_{l, t}\right)+\sum_{m} \widehat{F}_{m} \widehat{\gamma}_{m, t}+\right. \\
& \left.+\Phi_{t}-\sum_{m} \bar{C}_{m}\left(z_{m, t}-z_{m, t-1}\right)\right\rangle
\end{aligned}
$$

Subject to

$$
\begin{aligned}
& \Phi_{t}+\frac{\psi}{2} \beta_{i} A 2_{i, t}-D_{i, t} \bar{\omega}_{i, t} \leq \\
& \Phi_{t-1}+\frac{\psi}{2} \beta_{i} A 2_{i, t-1}-D_{i, t} \bar{\omega}_{i, t-1}(\forall t \geq 2), \Phi_{t=1}=0 \\
& (1 b)-(1 m)-(3 a)-(3 i) \\
& -\sum_{i} \frac{1}{2} \psi \beta_{i} A 2_{i, t}+\sum_{i} D_{i, t} \bar{\omega}_{i, t}+\sum_{j} G_{j} \bar{\nu}_{j, t}+ \\
& \sum_{l} F_{l}\left(\underline{\mu}_{l, t}+\bar{\mu}_{l, t}\right)+\sum_{m} \widehat{\gamma}_{m, t} \widehat{F}_{m} \\
& =\sum_{i}\left(\frac{1}{2} \psi \beta_{i} d 2_{i, t}+\psi \alpha_{i} d_{i, t}\right)-\sum_{j} \psi c_{j} g_{j, t}- \\
& \left.\sum_{k} \psi \widehat{c}_{k} \widehat{g}_{k, t}-\sum_{k} \underline{C}_{k}\left(\widehat{G}_{k, t}-\widehat{G}_{k, t-1}\right)\right\rangle \forall t \\
& \widehat{\gamma}_{m, t}-\left(\underline{\gamma}_{m, t}+\bar{\gamma}_{m, t}\right) \leq \Xi_{2}\left(1-z_{m, t}\right) \forall m, t \\
& \widehat{\gamma}_{m, t}-\left(\underline{\gamma}_{m, t}+\bar{\gamma}_{m, t}\right) \geq-\Xi_{2}\left(1-z_{m, t}\right) \forall m, t \\
& -\Xi_{2} z_{m, t} \leq \widehat{\gamma}_{m, t} \leq \Xi_{2} z_{m, t} \forall m, t \\
& A 2_{i, t} \geq A_{i, t}^{2}, d 2_{i, t} \geq d_{i, t}^{2} \forall i, t
\end{aligned}
$$

Where $\Omega_{p}=\Omega_{s} \cup\left\{A_{i, t}, A 2_{i, t}, d 2_{i, t}, \lambda_{n, t}, \underline{\omega}_{i, t}, \bar{\omega}_{i, t}, \underline{\nu}_{j, t}, \bar{\nu}_{j, t}\right.$

, $\left.\underline{\phi}_{k, t}, \bar{\phi}_{k, t}, \tau_{k, t}, \tau 0_{k}, \sigma_{l, t}, \underline{\mu}_{l, t}, \bar{\mu}_{l, t}, \underline{\sigma}_{m, t}, \bar{\sigma}_{m, t}, \underline{\gamma}_{l, t}, \bar{\gamma}_{l, t}, \xi 0_{t}\right\}$ is the set of decision variables of the optimization problem (7). The values $\Xi_{1}$ and $\Xi_{2}$ are suitably large constants. These constants must be selected carefully such that they do not impose extra bounds on variables (if they are selected too small) or result in 
ill-conditioning in the optimization problem (7) (if they are selected very large). The optimization program (7) is a MIQCP and can be solved using commercial solvers. The proposed approach for transmission expansion planning has the following sequence of actions:

1. The regulator sets the parameters $R$ and $Y$ in the regulatory constraint (2c). It also estimates the parameters $\alpha_{i}, \beta_{i}$ of linear demand functions using historic market prices [25], [7].

2. The Transco maximizes its profit over the planning periods taking regulatory constraint into account.

3. The Transco auctions off its (existing and expanded) transmission capacity as the point-to-point FTRs to market participants.

4. The Transco collects the merchandising surplus using the FTR auction in step 3 and sets the fixed charges according to the regulatory constraint.

5. The market operator distributes the merchandising surplus between FTR holders.

For sake of comparison, two existing approaches for regulating a Transco are also modeled.

1. Transco without regulation: In this case, the Transco is unregulated in terms of transmission expansion planning decisions. This case can be modeled by removing the revenue-cap regulatory constraint (7b) from optimization problem (7) and setting $\Phi_{t}=0$. In the no-regulation case, the cost of transmission expansion planning has to be fully recovered by congestion rents. Accordingly, the Transco will only expand such lines that increase congestion rent.

2. Transco with cost-plus regulation: In this case, the Transco receives not only the merchandising surplus but it can charge an extra fixed fee based on its cost of transmission expansion planning. This case can be modeled by replacing the regulatory constraint $(7 \mathrm{~b})$ by $\Phi_{t}=\Phi_{t-1}+(1+$ $r) \sum_{m} \bar{C}_{m}\left(z_{m, t}-z_{m, t-1}\right)$ where $r \in \mathbb{R}_{+}$is set by the regulator.

\section{Illustrative example}

The proposed mechanism for transmission expansion planning is applied to an illustrative two-node system. The single-line diagram and data of this example system is shown in Fig. 1. Four planning periods $\left(t_{1}, t_{2}, t_{3}, t_{4}\right)$ are considered and peak demand at each planning period is increased by $10 \%$ as compared to the previous period peak demand. Peak demand at first period $\left(\mathrm{t}_{1}\right)$ is $200 \mathrm{MW}$. Each planning year is represented by 500 identical hours $(\psi=500)$. The parameters

$\alpha_{i}$ and $\beta_{i}$ are calculated using $\alpha_{i}=\lambda_{\text {ref }}-D_{i} \beta_{i}$ and $\beta_{i}=\frac{\lambda_{r e f}}{\epsilon D_{i}}$ where $\lambda_{\text {ref }}$ is the 


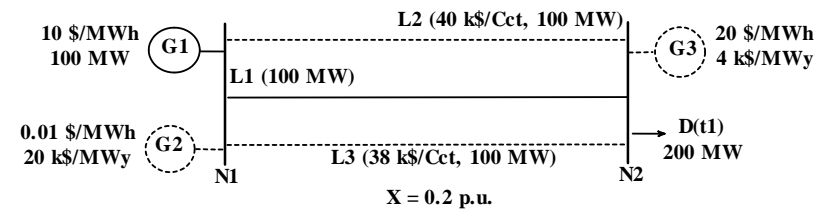

Figure 1: The illustrative 2-node system: Marginal costs in $\$ / M W h$, generation investment cost in $\mathrm{k} \$ / \mathrm{MWy}$, transmission investment cost in $\mathrm{k} \$ /$ Cct, capacities in MW, existing assets in solid lines, and candidate assets in dashed lines, Cct: Circuit
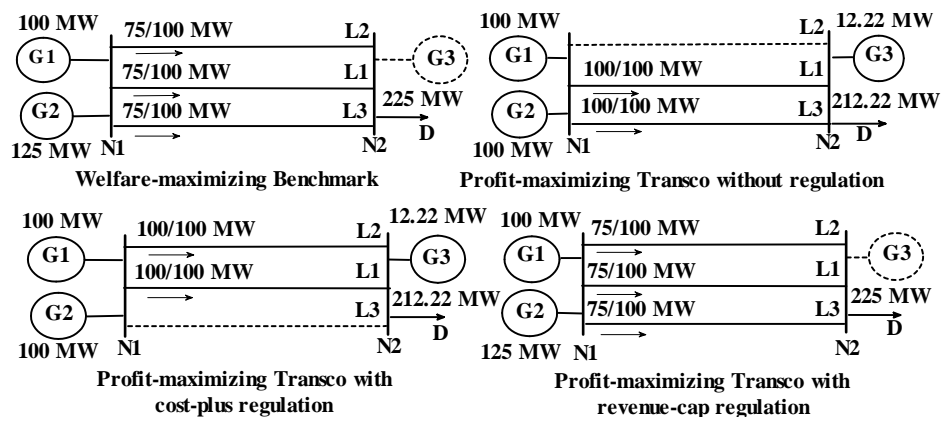

Figure 2: The power-flow results in period 4 under different regulatory regimes for two-node example system

reference price for the demand utility function and $\epsilon$ is the demand elasticity For all numerical examples $\lambda_{\text {ref }}=30 \$ / M W h$ and $\epsilon=-0.25$. The reported prices are nodal prices per planning year $\left(\lambda_{n, t}\right.$ in optimization $\left.(2 \mathrm{~d})-(2 \mathrm{e})\right)$.

As it is shown in Fig. 2, the Transco with revenue-cap regulation is incentivized to produce the results of the welfare-maximizing benchmark. The Transco without regulation invests in L3 and generators G2 and G3 react by expanding their generation capacities to $100 \mathrm{MW}$ and $12.22 \mathrm{MW}$, respectively. The Transco with cost-plus regulation invests in L2 and this results in $100 \mathrm{MW}$ and 12.22 MW generation capacities for G2 and G3, respectively. In both the no-regulation, and cost-plus regulation cases, existing and new lines are still congested and the served demand (212.22 MW) is less than the served demand in the revenue-cap regulation case $(225 \mathrm{MW})$. The Transco with cost-plus regulation selects the expensive candidate line (L2) for investment as compared to L3 selected in the no-regulation case. This is because the cost-plus regulated Transco is rewarded a portion of its investment cost. The expansion results over regulatory periods $\left(t_{1}, t_{2}, t_{3}, t_{4}\right)$ are set out in Table 1 for benchmark and revenue-cap cases, and in Table 2 for cost-plus and no-regulation cases. For the rest of the tables in this paper, BI, N-REG, CP-REG, and RC-REG stand for benchmark investment, no-regulation, cost-plus regulation, and revenue-cap regulation. Also, G-Plan, T-Plan, FC, TIC, GIC, TP, and SW stand for gen- 
Table 1: Dispatch and Investment results for BI and RC-REG (values inside []) over different regulatory periods for two-node system

\begin{tabular}{c|c|c|c|c}
\hline Periods & $\mathrm{t}_{1}$ & $\mathrm{t}_{2}$ & $\mathrm{t}_{3}$ & $\mathrm{t}_{4}$ \\
\hline G1(MW) & 100 & 95 & 100 & 100 \\
\hline G2(MW) & 0 & 125 & 125 & 125 \\
\hline G3(MW) & 0 & 0 & 0 & 0 \\
\hline L1(MW) & 100 & 73.33 & 75 & 75 \\
\hline L2(MW) & 0 & 73.33 & 75 & 75 \\
\hline L3(MW) & 0 & 73.33 & 75 & 75 \\
\hline N1(\$/MW) & 37,341 & 5,003 & 7,505 & 7,505 \\
\hline N2(\$/MW) & 46,182 & 5,004 & 7,505 & 7,505 \\
\hline FC $(\mathrm{k} \$)$ & {$[0]$} & {$[6,754]$} & {$[6,207]$} & {$[6,207]$} \\
\hline TIC $(\mathrm{k} \$)$ & 0 & 78 & 0 & 0 \\
\hline GIC $(\mathrm{M} \$)$ & 0 & 2.4995 & 0 & 0 \\
\hline SW $(\$)$ & $5,499,999$ & $6,186,750$ & $8,780,437$ & $8,780,437$ \\
\hline & \multicolumn{5}{r}{}
\end{tabular}

eration expansion plan, transmission expansion plan, fixed charge, transmission investment cost, generation investment cost, Transco profit, and social welfare, respectively. As we can see, the prices at nodes 1 and 2 converge to 7,505 $\$ / \mathrm{MW}$ in revenue-cap regulation while in the no-regulation or cost-plus regulation, there is a price difference of $4708 \$ / \mathrm{MW}(11333-6625)$ between nodes 1 and 2. The social welfare at period 4 for revenue-cap regulation is $\$ 8,780,437$ which is $\$ 242,234$ (8780437 - 8538203) higher than the social welfares for noregulation and cost-plus regulation.

\section{Numerical results}

To further investigate the proposed model, the Garver's 6-node and IEEE 24node systems are studied. The mathematical models are coded in GAMS and solved using CPLEX 12.6 solver. The simulations are run on a computer with a $2.7 \mathrm{GHz}$ processor and $16 \mathrm{~GB}$ of RAM.

\subsection{Modified Garver's 6-node example system}

This system has 6 nodes, and 7 existing transmission lines. In the modified system, line between nodes 4 and 6 is added to the existing transmission lines. The profit-maximizing Transco has 10 candidate transmission lines located between nodes $(2,3),(2,4),(2,5),(2,6),(3,4),(3,5),(3,6),(4,5),(4,6)$, and $(5,6)$ where pair $(x, y)$ means line from node $x$ to node $y$. There are two candidate generators at nodes 2 and 4 . The marginal costs for these generators are 0.01 and $0.02 \$ / \mathrm{MWh}$ with the investment cost of 20,000 and $4000 \$ / \mathrm{MWy}$. The $\psi$ is taken as 50. The rest of system data is the same as the one reported in [26]. Different regulatory regimes lead to different transmission expansion planning 
Table 2: Dispatch and Investment results for N-REG and CP-REG (values inside [1) over different regulatory periods for two-node system

\begin{tabular}{c|c|c|c|c}
\hline Periods & $\mathrm{t}_{1}$ & $\mathrm{t}_{2}$ & $\mathrm{t}_{3}$ & $\mathrm{t}_{4}$ \\
\hline $\mathrm{G} 1(\mathrm{MW})$ & 100 & 100 & 100 & 100 \\
\hline $\mathrm{G} 2(\mathrm{MW})$ & 0 & 100 & 100 & 100 \\
\hline $\mathrm{G} 3(\mathrm{MW})$ & 0 & 12.22 & 12.22 & 12.22 \\
\hline $\mathrm{L} 1(\mathrm{MW})$ & 100 & 100 & 100 & 100 \\
\hline $\mathrm{L} 2(\mathrm{MW})$ & $0[0]$ & $0[100]$ & $0[100]$ & $0[100]$ \\
\hline $\mathrm{L} 3(\mathrm{MW})$ & $0[0]$ & $100[0]$ & $100[0]$ & $100[0]$ \\
\hline $\mathrm{N} 1(\$ / \mathrm{MW})$ & 36,112 & 6,716 & 6,673 & 6,625 \\
\hline $\mathrm{N} 2(\$ / \mathrm{MW})$ & 45,000 & 11,333 & 11,333 & 11,333 \\
\hline $\mathrm{FC}(\mathrm{k} \$)$ & {$[0]$} & {$[48]$} & {$[48]$} & {$[48]$} \\
\hline $\mathrm{TIC}(\mathrm{k} \$)$ & 0 & $38[40]$ & 0 & 0 \\
\hline $\mathrm{GIC}(\mathrm{M} \$)$ & 0 & 2.0489 & 0 & 0 \\
\hline $\mathrm{SW}(\$)$ & $5,499,999$ & $6,451,314$ & $8,538,203$ & $8,538,203$ \\
& & {$[6,449,314]$} & & \\
\hline
\end{tabular}

Table 3: Investment results under different regulatory regimes for modified Garvers's system

\begin{tabular}{c|c|c|c|c}
\hline & BI & N-REG & CP-REG & RC-REG \\
\hline \multirow{2}{*}{ G-plan } & G4 & G4 & G4 & G4 \\
\cline { 2 - 5 } & $305 \mathrm{MW}$ & $306 \mathrm{MW}$ & $376 \mathrm{MW}$ & $293 \mathrm{MW}$ \\
\hline \multirow{2}{*}{ T-plan } & $(3,5)$ & $(2,5)$ & $(2,5),(3,4)$ & $(2,6),(3,5)$ \\
\cline { 2 - 5 } & & & $(3,6),(4,6)$ & $(3,6)$ \\
\hline FC $(\mathrm{k} \$)$ & 0 & 0 & 950.4 & 4565.9 \\
\hline TIC $(\mathrm{k} \$)$ & 20 & 60 & 198 & 80 \\
\hline GIC $(\mathrm{M} \$)$ & 1.2225 & 1.2245 & 1.5064 & 1.1736 \\
\hline TP $(\mathrm{M} \$)$ & - & 1.9373 & 2.4137 & 5.4787 \\
\hline SW $(\mathrm{M} \$)$ & 10.146 & 9.857981 & 9.648374 & 10.10564 \\
\hline
\end{tabular}

strategies. This in turn results in different investment reactions by generators. These investment strategies are reported in Table 3.

As in Table 3, the Transco with revenue-cap regulation while maximizing its own profit achieves the closest system social welfare $(10.10564 \mathrm{M} \$$ ) to the benchmark social welfare $(10.146 \mathrm{M} \$)$. For this system, the Transco with no-regulation is the second best (with social welfare of $9.857981 \mathrm{M} \$$ ), and the Transco with cost-plus regulation is the third best (with social welfare of $9.648374 \mathrm{M} \$$ ). The nodal prices in period $t_{4}$ are shown in Table 4. As this table shows the average of nodal prices $\left(\frac{\sum_{n} \lambda_{n}}{N}\right)$ under the proposed approach for transmission expansion planning is closest to the benchmark nodal prices. 
Table 4: Nodal prices $(\$ / M W)$ in period 4 under different regulatory regimes for modified Garvers' system

\begin{tabular}{c|c|c|c|c}
\hline Approach & BI & N-REG & CP-REG & RC-REG \\
\hline N1 & 1256 & 2292 & 2299 & 1187 \\
\hline N2 & 1545 & 1982 & 1898 & 1377 \\
\hline N3 & 1000 & 1000 & 1000 & 1000 \\
\hline N4 & 1334 & 1334 & 1334 & 1278 \\
\hline N5 & 1085 & 2767 & 2821 & 1063 \\
\hline N6 & 1334 & 1334 & 1254 & 1250 \\
\hline Avg. & 1888 & 2677 & 2651 & 1788 \\
\hline
\end{tabular}

Table 5: Candidate transmission lines for modified IEEE 24-node system, Cct: Circuit

\begin{tabular}{c|c|c|c}
\hline (from-to $)$ & $\mathrm{X}(\mathrm{pu})$ & $\bar{C}_{m}(\mathrm{M} \$ / \mathrm{Cct})$ & $\widehat{F}_{m}(\mathrm{MW})$ \\
\hline$(15,21)$ & 0.049 & 24.81 & 166 \\
\hline$(15,24)$ & 0.0519 & 26.27 & 166 \\
\hline$(16,17)$ & 0.0259 & 13.11 & 166 \\
\hline$(16,19)$ & 0.0231 & 11.70 & 166 \\
\hline$(17,18)$ & 0.0144 & 7.29 & 166 \\
\hline$(17,22)$ & 0.1053 & 53.31 & 166 \\
\hline$(18,21)$ & 0.0259 & 13.11 & 166 \\
\hline$(19,20)$ & 0.0396 & 20.05 & 166 \\
\hline$(20,23)$ & 0.0216 & 10.93 & 166 \\
\hline$(21,22)$ & 0.0678 & 34.32 & 166 \\
\hline
\end{tabular}

\subsection{Modified IEEE 24-node example system}

The initial network topology is the one reported in [27] and 10 candidate transmission lines as specified in Table 5 are considered. The generation system is modified as reported in Table 6 and 7 . The rest of data is the one reported in [19]. The $\psi$ is set at 5000 .

The total load is $2850 \mathrm{MW}$, which corresponds to the Tuesday of week 51 from 5 to $6 \mathrm{pm}$. The Transco plans under different regulatory regimes and the various generation investment choices are reported in Table 8 .

The results for the profit-maximizing Transco with revenue-cap regulation are the same as the benchmark results. The case without regulation is the second best and the case with the cost-plus regulation is in the third place in terms of social welfare. The Transco with cost-plus regulation has the highest cost of transmission expansion planning and the one without regulation has the lowest transmission expansion cost. These results are expected. In the case of costplus regulation, the Transco is rewarded based on its transmission investment cost, and in the no-regulation case, the Transco invests in lines which increases congestion rent and it does not relieve congestion from system. The profile of 
Table 6: Generators' data for modified IEEE 24-node system

\begin{tabular}{c|c|c|c|c|c|c|c}
\hline Gen. & Node & $c_{j}$ & $G_{j}$ & Gen. & Node & $c_{j}$ & $G_{j}$ \\
\hline & & $(\$ / \mathrm{MWh})$ & $(\mathrm{MW})$ & & & $(\$ / \mathrm{MWh})$ & $(\mathrm{MW})$ \\
\hline G1 & 1 & 130 & 40 & G8 & 8 & 12 & 310 \\
\hline G2 & 1 & 16 & 152 & G9 & 9 & 4 & 800 \\
\hline G3 & 2 & 130 & 40 & G10 & 22 & 0.001 & 300 \\
\hline G4 & 2 & 16.2 & 152 & G11 & 23 & 12 & 310 \\
\hline G5 & 7 & 43 & 300 & G12 & 23 & 11 & 350 \\
\hline G6 & 6 & 48.1 & 591 & G13 & 15 & 0.001 & 100 \\
\hline G7 & 7 & 56.1 & 60 & G14 & 16 & 0.002 & 100 \\
\hline
\end{tabular}

Table 7: Candidate Generators for modified IEEE 24-node system

\begin{tabular}{c|c|c|c}
\hline Gen. & Node & $\widehat{c}_{k}(\$ / \mathrm{MWh})$ & $\underline{C}_{k}(\mathrm{k} \$ / \mathrm{MW})$ \\
\hline G15 & 3 & 0.001 & 700 \\
\hline G16 & 5 & 0.002 & 300 \\
\hline G17 & 10 & 0.003 & 20,000 \\
\hline G18 & 15 & 0.004 & 30,000 \\
\hline G19 & 20 & 0.005 & 15,000 \\
\hline
\end{tabular}

Table 8: Investment results under different regulatory regimes for the modified IEEE 24-node system

\begin{tabular}{c|c|c|c|c}
\hline & BI & N-REG & CP-REG & RC-REG \\
\hline \multirow{4}{*}{ G-plan } & G15 & G15 & G15 & G15 \\
\cline { 2 - 5 } & $123.1 \mathrm{MW}$ & $116.5 \mathrm{MW}$ & $119.6 \mathrm{MW}$ & $123.1 \mathrm{MW}$ \\
\cline { 2 - 5 } & G16 & G16 & G16 & G16 \\
\cline { 2 - 5 } & $93.5 \mathrm{MW}$ & $93.2 \mathrm{MW}$ & $97 \mathrm{MW}$ & $93.5 \mathrm{MW}$ \\
\hline \multirow{2}{*}{ T-plan } & $(19,20)$ & $(16,19)$ & $(15,21)(15,24)$ & $(19,20)$ \\
\cline { 2 - 5 } & $(20,23)$ & & $(16,17)(16,19)$ & $(20,23)$ \\
\cline { 2 - 5 } & & & $(18,21)(19,20)$ & \\
\hline FC $(\mathrm{M} \$)$ & - & - & 418.83 & 406.92 \\
\hline TIC $(\mathrm{M} \$)$ & 30.980 & 11.700 & 116.34 & 30.980 \\
\hline GIC $(\mathrm{M} \$)$ & 114.27 & 109.49 & 112.86 & 114.27 \\
\hline TP $(\mathrm{M} \$)$ & - & 1197.5 & 1498.0 & 1530.8 \\
\hline SW $(\mathrm{M} \$)$ & 4125.455 & 3979.628 & 3855.140 & 4125.455 \\
\hline
\end{tabular}




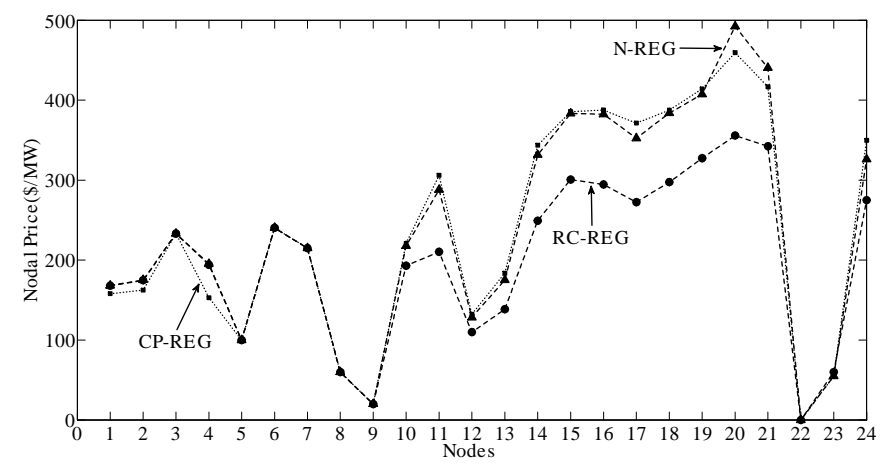

Figure 3: The nodal prices under different regulatory regimes in planning period 4 for the modified IEEE 24-node system

nodal prices at period $t_{4}$ for different nodes under different regulatory regimes are plotted in Fig. 3.

As it is clear from Fig. 3, the Transco with revenue-cap regulation achieves the lowest electricity prices. The average of nodal prices for revenue-cap regulation is $201 \mathrm{k} \$ / \mathrm{MW}$ while for cost-plus regulation and no-regulation, it is 240 $\mathrm{k} \$ / \mathrm{MW}$. This is equivalent to a $20 \%$ increase in average prices.

\section{Further Discussions}

The proposed approach for transmission expansion planning is analyzed under two other realistic situations. First, it is assumed that the generation system is static and transmission expansion planning is only driven by demand growth. Second, we take the view of a reactive Transco where the generation investments are exogenous parameters.

\subsection{Case 1: Transmission expansion planning driven by demand growth}

For this study, only existing generators of the modified Garver's system are considered. The rest of the system data are those specified in Section 6. The results of transmission expansion planning under different regulatory regimes are reported in Table 9. The Transco without regulation does not invest in any new transmission lines. This is because investing in any transmission line reduces the overall system congestion rent. The profit of the Transco is 3.1379 $\mathrm{M} \$$ and the social welfare is $8.980316 \mathrm{M} \$$. The Transco with cost-plus regulation invests in five new lines as reported in Table 9 with investment cost of $237 \mathrm{M} \$$. The Transco profit with cost-plus regulation is higher than one for the case with no-regulation but at the cost of decreased social welfare. However, the revenue-cap regulation approach results in the benchmark solution. In terms of 
Table 9: Transmission investment under different regulatory regimes for modified Garver's example system - case 1

\begin{tabular}{c|c|c|c|c}
\hline & BI & N-REG & CP-REG & RC-REG \\
\hline \multirow{2}{*}{ T-plan } & $(2,6)$ & - & $(2,4)(2,5)$ & $(2,6)$ \\
\cline { 2 - 5 } & $(3,5)$ & - & $(3,4)(3,6)$ & $(3,5)$ \\
\cline { 2 - 5 } & $(4,6)$ & - & $(4,5)$ & $(4,6)$ \\
\hline $\mathrm{FC}(\mathrm{k} \$)$ & - & - & 853.2 & 3877.2 \\
\hline $\mathrm{TIC}(\mathrm{k} \$)$ & 70 & 0 & 237 & 70 \\
\hline $\mathrm{TP}(\mathrm{M} \$)$ & - & 3.1379 & 3.6930 & 5.1022 \\
\hline $\mathrm{SW}(\mathrm{M} \$)$ & 9.975325 & 8.980316 & 8.912756 & 9.975325 \\
\hline $\mathrm{Avg}(\$ / \mathrm{MW})$ & 1435 & 2925 & 2755 & 1435 \\
\hline
\end{tabular}

Table 10: Transmission investment under different regulatory regimes for the modified IEEE 24-node system - case 1

\begin{tabular}{c|c|c|c|c}
\hline & BI & N-REG & CP-REG & RC-REG \\
\hline \multirow{2}{*}{ T-plan } & $(19,20)$ & $(19,20)$ & $(15,21)(15,24)(16,17)$ & $(19,20)$ \\
\cline { 2 - 5 } & $(20,23)$ & $(20,23)$ & $(16,19)(17,18)(18,21)$ & $(20,23)$ \\
\cline { 2 - 5 } & & $(17,18)$ & $(19,20)(20,23)$ & \\
\hline FC $(\mathrm{M} \$)$ & - & - & 458.16 & 148.15 \\
\hline TIC $(\mathrm{M} \$)$ & 30.98 & 38.270 & 127.27 & 30.98 \\
\hline $\mathrm{TP}(\mathrm{M} \$)$ & - & 1233.4 & 1614.4 & 1389.3 \\
\hline $\mathrm{SW}(\mathrm{M} \$)$ & 4016.828 & 4015.358 & 3911.275 & 4016.828 \\
\hline $\mathrm{Avg}(\$ / \mathrm{MW})$ & 243 & 243 & 246 & 243 \\
\hline
\end{tabular}

nodal prices, the average price for Transco with revenue-cap regulation is the cheapest as compared to ones for no-regulation and cost-plus regulation cases (1435 \$/MW as compared to $2925 \$ / \mathrm{MW}$ and $2755 \$ / \mathrm{MW}$ ). Table 10 reports the results for the modified IEEE 24-node system.

The proposed Transco invests $30.98 \mathrm{M} \$$ in transmission system expansion and collects a profit of $1389.3 \mathrm{M} \$$ which includes a total fixed charge of 148.15 $\mathrm{M} \$$. The social welfare is $4016.828 \mathrm{M} \$$ which is the benchmark social welfare. Average price in this case is $243 \$ / \mathrm{MW}$. In cases of no-regulation and cost-plus regulation, the Transco invests $38.27 \mathrm{M} \$$ and $127.27 \mathrm{M} \$$ in transmission system which are higher than the benchmark cost. Accordingly the social welfare in these cases are less than the benchmark social welfare.

\subsection{Case 2: Reactive Transco with exogenous generation investments}

In this case, the capacity of existing generators for the modified Garver's system and modified IEEE 24-node system are increased by $15 \%$ in each planning year. The results are reported in Tables 11 and 12. For this case, the proposed model has the closest social welfare to the benchmark welfare. In terms of average 
Table 11: Transmission investment under different regulatory regimes for the modified Garvers' system - case 2

\begin{tabular}{c|c|c|c|c}
\hline & BI & N-REG & CP-REG & RC-REG \\
\hline \multirow{2}{*}{ T-plan } & $(2,3)$ & $(2,4)$ & $(2,4)(2,5)$ & $(2,3)$ \\
\cline { 2 - 5 } & $(2,6)$ & & $(3,4)(3,6)$ & $(2,6)$ \\
\cline { 2 - 5 } & $(3,5)$ & & $(4,5)$ & $(3,5)(4,6)$ \\
\hline $\mathrm{FC}(\mathrm{k} \$)$ & - & - & 853.2 & 4249.2 \\
\hline $\mathrm{TIC}(\mathrm{k} \$)$ & 80 & 38 & 237 & 110 \\
\hline $\mathrm{TP}(\mathrm{M} \$)$ & - & 2.7787 & 3.3304 & 5.2680 \\
\hline $\mathrm{SW}(\mathrm{M} \$)$ & 10.23066 & 9.344380 & 9.285405 & 10.15882 \\
\hline $\operatorname{Avg}(\$ / \mathrm{MW})$ & 1312 & 2554 & 2375 & 1317 \\
\hline
\end{tabular}

Table 12: Transmission investment under different regulatory regimes for the modified IEEE 24-node system - case 2

\begin{tabular}{c|c|c|c|c}
\hline & BI & N-REG & CP-REG & RC-REG \\
\hline \multirow{2}{*}{ T-plan } & $(19,20)$ & - & $(15,21)(15,24)(16,17)$ & $(19,20)$ \\
\cline { 2 - 5 } & $(20,23)$ & - & $(16,19)(17,18)(17,22)$ & $(20,23)$ \\
\cline { 2 - 5 } & $(21,22)$ & - & $(18,21)(19,20)(20,23)$ & $(17,22)$ \\
\hline FC $(\mathrm{M} \$)$ & - & - & 570.39 & 331.23 \\
\hline TIC $(\mathrm{M} \$)$ & 65.300 & 0 & 180.58 & 84.29 \\
\hline $\mathrm{TP}(\mathrm{M} \$)$ & - & 1223.3 & 1667.7 & 1512.6 \\
\hline $\mathrm{SW}(\mathrm{M} \$)$ & 4136.749 & 3958.543 & 3993.819 & 4091.041 \\
\hline $\begin{array}{c}\text { Avg } \\
(\mathrm{k} \$ / \mathrm{MW})\end{array}$ & 192 & 253 & 208 & 208 \\
\hline
\end{tabular}

nodal prices for period $t_{4}$, both revenue-cap and cost-plus regulation prices (208 $\mathrm{k} \$ / \mathrm{MW})$ are closest to the benchmark price $(192 \mathrm{k} \$ / \mathrm{MW})$.

\section{Conclusions}

This paper proposes a profit-maximizing approach for transmission expansion planning. The Transco expands the transmission network over planning periods, collects merchandising surplus, and charges fixed fees to consumers. This is subject to a proposed revenue-cap constraint set by the regulator. The proposed approach is a bilevel program with a profit-maximizing Transco at the upper level and optimal generation dispatch and investment at the lower level. The whole proposed mechanism is reformulated as a mixed-integer, quadraticallyconstrained program (MIQCP) which can be solved to global optimality. Also, the model considers the discrete nature of transmission planning decisions and potential substitution between transmission expansion and generation expansion. The mechanism has been applied and tested on a modified Garvers' system as well as a modified IEEE 24 -node system. In all tests, the proposed mecha- 
nism incentivizes Transco to produce welfare-maximum outcomes. We further have tested the proposed mechanism under cases where transmission expansion planning is driven by demand growth and reactive Tranco. The welafremaximum outcomes are also achieved under these two cases. The results imply that the proposed mechanism can tackle the incentive problem for investment in transmission sector. Application of the stochastic programming models to the proposed approach in the paper is a good extension of this work.

\section{References}

[1] P. Joskow, "The difficult transition to competitive electricity markets in the US" Electricity Deregulation: Choices and Challenges, Edited by Griffin and S. Puller, University of Chicago Press, 2005

[2] J. Dyer, "US Department of Energy Transmission Bottleneck Project Report", Consortium for Electric Reliability Technology Solution (CERTS), 2003

[3] - "Towards a Common Co-Ordinated Regional Congestion Management in Europe", Consentec study commissioned by the European Commission, Aachen, Germany 2003

[4] T-O. Leautier, "Transmission constraints and imperfect markets for power," J Regul Econ, vol. 19, no.1, pp. 27-54, 2001

[5] I. Vogelsang, "Electricity transmission pricing and performance-based regulation," Energy Journal, vol. 27, no.4, pp.97-126, 2006

[6] R. Wilson, "Architecture of power markets," Econometrica, Vol.40, No. 4, pp. 1299-1340, 2002

[7] D Sappington, D Sibley, "Regulating without COST information: the incremental surplus subsidy scheme" Int Econ Rev, vol. 32, no. 1, pp. 119-148, Janury 2002

[8] I. Vogelsang, "Price regulation for independent transmission companies" Journal of Regulatory Economics., vol. 20, no. 2, pp. 141-65, 2001

[9] M Tanaka, "Extended price cap mechanism for efficient transmission expansion under nodal pricing " Netw Spatial Econ, vol. 7, pp. 257-275, 2007

[10] W. Hogan, J. Rosellon, I. Vogelsang, "Toward a combined merchantregulatory mechansim for electricity transmission expansion", Journal of Regulatory Economics., vol. 38, no. 2, pp. 113-143, 2010

[11] P. Joskow, and J. Tirole, "Transmission investment: Alternative institutional frameworks" Conference proceedings: Wholesale Markets for Electricity, Nov 22-23, 2002, Toulous, France 
[12] T. O. Leautier, "Regulation of an electric power transmission comapny" The Energy Journal, vol. 21, no. 4, pp. 61-92, 2000

[13] T. Kristiansen, and J. Rosellon, "A merchant mechanism for electricity transmission expansion" Journal of Regulatory Economics., vol. 29, no. 2, pp. 167-193, 2006

[14] W. Hogan, "Financial transmission right formulations" JFK School of Government, www.ksg.harvard.edu/people/whogan, 2002

[15] J. Rosellin, and H. Weigt, "A combined merchant-regulatory mechansim for electricity transmission expansion in Europe“, Energy Journal., vol. 32, no. 1, pp. 119-148, 2011

[16] J. Rosellón, Z. Myslíková, and E. Zenón, "Incentives for transmission investment in the PJM electricity market: FTRs or regulation (or both?) ", Utilities Policy, vol. 19, no. 1, pp. 3-13, January 2011

[17] R. Baldick, and E. Kahn, "Network costs and the regulation of wholesale competition in electric power" Journal of Regulatory Economics., vol. 5, no. 4, pp. 367-384, 1993

[18] S. Binato, M.V.F Pereira, S. Granville, "A new Benders decomposition approach to solve power transmission network design problems," Power Systems, IEEE Transactions on, vol.16, no.2, pp.235,240, May 2001

[19] N. Alguacil, A. L. Motto, A. J. Conejo, "Transmission expansion planning: a mixed-integer LP approach," Power Systems, IEEE Transactions on , vol.18, no.3, pp.1070-1077, Aug. 2003

[20] D. P. Bertsekas, Nonlinear programming, Athena Scientific; 2nd edition, September 1999)

[21] J. F. Bard, Practical Bilevel Optimization Algorithms and Applications, Kluwer Academic Publishers; 1st edition, 1999

[22] C. Ruiz, A. J. Conejo, "Pool Strategy of a Producer With Endogenous Formation of Locational Marginal Prices," Power Systems, IEEE Transactions on , vol. 24, no. 4, pp. 1855-1866, Nov. 2009

[23] E. Moiseeva, M. R. Hesamzadeh, D. R. Biggar, "Exercise of Market Power on Ramp Rate in Wind-Integrated Power Systems," Power Systems, IEEE Transactions on, vol.PP, no.99, pp.1-10

[24] J. Fortuny-Amat and B. McCarl, "A representation and economic interpretation of a two-level programming problem," Journal of the operational Research Society, vol. 32, no. 9, pp.783-792, Sep. 1981.

[25] W-P. Schill, J. Egerer, J. Rosellón, "Testing regulatory regimes for power transmission expansion with fluctuating demand and wind generation", Journal of Regulatory Economics, vol. 47, no. 1, pp 1-28, Feb. 2015 
[26] R. Romero, A. Monticili, A. Garcia, and S. Haffner, "Test systems and mathematical models for transmission network expansion planning " IEE Proc.-Gener. Transm. Distrib., vol. 149, no. 1, Jan. 2002

[27] "IEEE Reliability Test System," Power Apparatus and Systems, IEEE Transactions on , vol. PAS-98, no. 6, pp. 2047-2054, Nov. 1979 